Historic, Archive Document

Do not assume content reflects current scientific knowledge, policies, or practices. 


\section{SURPLUS LIST}

of good Seed grown under Irrigation, in $100 \mathrm{lb}$. lots at the following prices:

1000 lbs. Rocky Ford Cantaloupe 500 lbs Osage Gem 500 lbs Kleckley Sweet Watermelon 500 lbs Boston Pickling Cucumber $24 c$ per lb 600 lbs White Spine 200 lbs Early Fortune

"6

6 $35 \mathrm{c}$ per lb $30 \mathrm{c}$ per lb 30 c per lb 30 c per lb

O. W. WEST,

R. D. No. 3 .

Dec. 22, 1910. 
